\title{
Run the Experiment, Publish the Study, Close the Sale: Business, Values, Science and Biomedical Research
}

\author{
Aleta Quinn
}

\begin{abstract}
Business models for biomedical research prescribe decentralization due to market selection pressures. I argue that decentralized biomedical research does not match four normative philosophical models of the role of values in science. Non-epistemic values affect the internal stages of for-profit biomedical science. Publication planning, effected by Contract Research Organizations, inhibits mechanisms for transformative criticism. The structure of contracted research precludes attribution of responsibility for foreseeable harm resulting from methodological choices. The effectiveness of business strategies leads to overrepresentation of profit values versus the values of the general public. These disconnects in respect to the proper role of values in science results from structural issues ultimately linked to the distinct goals of business versus applied science, and so it seems likely that disconnects will also be found in other dimensions of attempts to combine business and science. The volume and integration in the publishing community of decentralized biomedical research imply that the entire community of biomedical research science cannot match the normative criteria of community-focused models of values in science. Several proposals for changing research funding structure might successfully relieve market pressures that drive decentralization.
\end{abstract}

\section{Introduction}

Goldacre and Reiss and Kitcher describe a variety of problems arising through the commercialization of biomedical research. ${ }^{1}$ Innovation is neglected in favor of intellectual property rent-seeking behavior and development of 'me-too' drugs. The effect size of new drugs is overstated while important side effects are unnoticed. Some 'diseases' are invented and marketed via direct-to-consumer advertising.

1 Ben Goldacre, Bad Pharma: How Drug Companies Mislead Doctors and Harm Patients (New York: Faber \& Faber, 2014); Julian Reiss and Philip Kitcher, 'Biomedical Research, Neglected Diseases, and Well-Ordered Science', Theoria 24:3 (2009), pp. 263-282. 
Given the high toll in human suffering caused by these problems, moral outrage is unsurprising. As Reiss points out, however, philosophers of science are uniquely positioned to address not just the ethical but also the epistemic short-comings of the current system of biomedical research. ${ }^{2}$ Ethical critiques tend to focus either on the overall injustice of the distribution of resources or on ethical lapses of particular individuals engaged in research. This paper argues that a more structural approach is needed. Both epistemic and ethical problems in US biomedical research arise not from individual greed but from the nature of the institutions engaged in biomedical research. Goldacre has pointed out that 'it's possible for good people, in perversely designed systems, to casually perpetrate acts of great harm on strangers, sometimes without ever realizing it.' ${ }^{3}$ The phrase 'perversely designed' suggests that the systems in question arose through deliberate intent. It is critical both to the diagnosis and resolution of problems in biomedical research to understand certain structural problems as having evolved without intentional design.

The structure of U.S. biomedical research qua business follows from its purpose. The ultimate goal is profit. For simplicity, this paper focuses on the case of a pharmaceutical company pursuing profit via drug sales. A further source of revenue patenting and licensing research methodologies - arises alongside drug development. I begin, in section 2, by examining the structure of Contract Research Organizations (CROs), focusing on publication planning in particular. For economic reasons, pharmaceutical companies increasingly turn to CROs as the most efficient biomedical research business model.

In section 3 I consider the goal of applied science and how the problems with contemporary biomedical research are both epistemic and ethical. Failure to meet the goal of applied science stems from an inappropriate intrusion of nonepistemic values in commercialized research. I show that research on the CRO fails to match the role of values in science prescribed by a traditional, externalist model of applied science. I elucidate the problematic role of nonepistemic values by showing that biomedical research on the business model violates each of the roles for non-epistemic values prescribed by Longino, Douglas, and Elliott. ${ }^{4}$ The structure of biomedical research (BMR) businesses, which ultimately stems from the goal of BMR business, currently cannot meet the normative standards described by these philosophical models of the role of nonepistemic values in science. I conclude by identifying two proposed interventions that would alleviate the problematic role of nonepistemic values in US biomedical research.

2 Julian Reiss, 'In Favour of a Millian Proposal to Reform Biomedical Research', Synthese 177:3 (2010), pp. pp. 427-447.

3 Goldacre, Bad Pharma, p. xi.

${ }^{4}$ Helen E. Longino, Science as Social Knowledge: Values and Objectivity in Scientific Inquiry (Princeton: Princeton University Press, 1990); Heather Douglas, Science, Policy, and the Value-Free Ideal (Pittsburgh, PA: University of Pittsburgh Press, 2009); Kevin Christopher Elliott, Is a Little Pollution Good for You? Incorporating Societal Values in Environmental Research (Oxford: Oxford University Press, 2010). 


\section{Biomedical Research as Business: Contract Research Organizations}

Since the 1980s, large pharmaceutical companies have increasingly out-sourced aspects of BMR business. ${ }^{5}$ Mirowski and Van Horn showed that out-sourcing is a response to globalization, regulatory pressures, and broad market trends. ${ }^{6}$ For example, beginning in 1981 the FDA permitted Institutional Review Boards (IRBs) to operate independently, on a for-profit basis. However, universities and companies that already used their own dependent IRBs as of 1981 could not employ the new, independent IRBs. The independent IRBs tended to approve studies faster due to market selection pressure. Consequently, it became advantageous for pharmaceutical companies, whose own research would be tied to dependent IRBs, to out-source trials to companies that could employ the independent IRBs.

The 1990s saw the rapid growth of Contract Research Organizations (CROs): companies that the pharmaceutical giants contract to conduct drug research, clinical trials, and disseminate research results via publication planning. Sismondo reported that about $70 \%$ of pharmaceutical industry research funding goes to Contract Research Organizations. ${ }^{7}$ Pharmaceutical giants can decrease or eliminate their own in-house research, thereby avoiding the costs of keeping up with new technology. On the CRO model, research can be spread out over many geographic sites. CROs can maintain facilities and provide local expertise in countries that have weaker regulatory structures. Particular methodological requirements (e.g. that patients receive the best available treatment rather than placebo), conflict of interest reporting, and trial registration requirements can be avoided. The economic benefit to the pharmaceutical sponsor is that these trials are faster, and data and results can be chosen from the most positive trials only. Trials that are not generating positive results can simply be terminated. Research funding is thus more efficiently spent.

A CRO can handle all phases of drug development, from initial molecule testing to each clinical trial phase and beyond. The CRO develops the research design and all subsequent research decisions. Some details of how the CRO proceeds are critical. Each research step proceeds precisely according to the initial design. The CRO delivers the trial data following the contract 'line-by-line'; 'anything beyond the contract, you do not get'. 8 Often there are no incentives for employees to notice unexpected results, ask questions outside the narrow bounds of their tasks, or report potential problems. To a large extent there are no opportunities for employees to notice potential problems because each individual task is performed in isolation from other study tasks, without knowledge of how the task fits into the overall study.

5 Philip Mirowski and Robert Van Horn, 'The Contract Research Organization and the Commercialization of Scientific Research', Social Studies of Science 35:4 (2005), pp. 503-548; Joel Lexchin, 'Clinical Trials in Canada: Whose Interests Are Paramount?', International Journal of Health Services 38:3 (2008), pp. 525-542; Gary Pisano, 'Can Science Be a Business?', Harvard Business Review 84:10 (2006), p. 114.

${ }^{6}$ Mirowski and Van Horn, 'The Contract Research Organization and the Commercialization of Scientific Research'.

7 Sergio Sismondo, 'Ghost Management: How Much of the Medical Literature Is Shaped Behind the Scenes by the Pharmaceutical Industry?', PLoS Medicine 4:9 (2007), e286.

8 Pierre Azoulay, 'Capturing Knowledge within and across Firm Boundaries: Evidence from Clinical Development', The American Economic Review 94:5 (2004), pp. 1591-1612. 
No single scientist need know the results at all geographic sites or for all clinical trials. Each task of the project can be performed completely independently. There is no opportunity for a scientist to notice outliers or trends that might indicate study contamination or bias. Indeed, it is possible in such a diffuse system for bias to accumulate at all levels. Methodological decisions that, taken individually, seem to involve only minor potential bias can add together to generate skewed results overall. This overall bias results from the structure of the enterprise itself: there is no single scientist responsible for the significant end-result.

Not only the clinical trials themselves but the dissemination of research results can be contracted out. Many CROs offer publication planning, which can also be contracted to independent Medical Communications companies. Publication planning involves both preparing individual studies and coordinating journal submission strategies.

Each individual study may be written by multiple people. Under the current system, it is in fact very difficult to determine who writes a study. Increasingly, however, the named study author will have had very little to do with either the research or the writing. Sismondo estimated that $75 \%$ of industry-funded publications are ghostwritten, ${ }^{9}$ while Elliott suggested the figure might be as high as $90 \% .{ }^{10}$ From a business perspective, hiring a well-known, respected named author lends weight to the study. The persons who performed tasks within the clinical trial are not likely to be involved in writing the study. There is no reason to involve study designers or lab technicians in the writing, which is best done by professional medical writers with an eye toward the goal of study publication. The purpose of publication in turn relates either to winning FDA approval, or leading doctors to prescribe the favored drug. The person or persons who write the study have no interest in gaining scientific or academic credit; they are simply paid to write the manuscripts. The overall result of all this diffusion is that no single individual meets the requirements of study authorship set by the International Committee of Medical Journal Editors. ${ }^{11}$ These requirements include (1) contributing to the study design or data acquisition, analysis, or interpretation; (2) writing or critically reviewing the manuscript; (3) approving the final draft; and (4) agreeing to bear responsibility for the accuracy and integrity of the work reported. In the case of ghostwriting by publication planners, there is no single person hiding behind the curtain - the 'ghost' is truly a non-person.

Publication planners coordinate manuscript submissions in order to achieve effective timing and an effective spread of journals, authors, and topics. Again the goal is either (or both) FDA approval and promoting the drug to medical professionals. The latter goal suggests that the purpose of study publication is, in fact, marketing. Publication planners are at pains to deny this charge. In arguing that publication planning is a form of marketing, ${ }^{12}$ Sismondo and Nicholson cite the publication planning section of a CRO website, that advises that '[d]ata generated from clinical trials are the

9 Sismondo, 'Ghost Management'.

10 Elliott, Is a Little Pollution Good for You?

11 International Committee of Medical Journal Editors, 'Defining the Role of Authors and Contributors', online at http://www.icmje.org/recommendations/browse/roles-andresponsibilities/defining-the-role-of-authors-and-contributors.html (accessed 2016-06-10).

12 Sergio Sismondo and Scott Howard Nicholson, 'Publication Planning 101', Journal of Pharmacy $\mathcal{E}$ Pharmaceutical Sciences 12:3 (2009), pp. 273-279. 
most powerful marketing tools available to a pharmaceutical company.' Publication planning offers 'message development and allocation'. ${ }^{13}$ Browsing the same site by means of the Internet Archive Project (web.archive.org), one finds that by 2009 'the most powerful marketing tools' has been replaced by 'the most powerful publication tools'. 'Message development and allocation' has been replaced by 'Scientific finding development and allocation'. ${ }^{14}$

In 2002, during the course of Motus v. Pfizer, Pfizer was compelled to produce a document that illustrates the extent of publication planning. The document reports the status of eighty-five studies on Zoloft (sertraline) funded by Pfizer, using several CROs (vendors). At the time, these studies represented a significant portion of the entire published literature on sertraline. Submissions to different journals were clearly coordinated - for example, one study's submission status was listed as 'on hold' until another study had been submitted (the document can be viewed at David Healy's website). ${ }^{15}$ The most effective business strategy for publishing studies involves careful selection of study author and professional writers, and the coordination of multiple publications in terms of timing and journal selection in order to convey the advertising message: the FDA should approve, and doctors should prescribe, the study drug.

Overall, the BMR business model involves diffusion at all levels. All functions of drug development are strategically separated, with each employee performing a narrow, specialized task. This structure results not from individual greed, but from effective and inevitable response to market conditions. Businesses that do not effectively strategize BMR fail; indeed, Pisano claims that most biotech firms earn no profit. ${ }^{16}$

The fact that Envision Pharma replaced marketing terms with non-marketing terms suggests both a faith and a worry. The faith is that it is irrelevant whether one describes an activity as 'marketing' or 'publication', and an item as 'message' or 'scientific finding'. The worry is that the company saw the need to change the wording to combat the perception that marketing values are corrupting research. As will be seen below, the perception is well-founded. In the next section I identify problems with the business model as failures to meet the goal of applied science. I then use philosophical models of the role of values in science to elucidate the ways in which the intrusion of marketing values is indeed problematic for research on the CRO model.

13 Envision Pharma, 'Publications Planning', http://envisionpharma.com/publicationsplanning/, 27 September 2008, online at https:/ / web.archive.org/web/20080927093133/http:/ /www. envisionpharma.com/publicationsPlanning (accessed 2016-06-22).

14 Envision Pharma, 'Publications Planning', http://envisionpharma.com/publicationsplanning/, 31 March 2009, online at https://web.archive.org/web/20090331060139/http:/ / www. envisionpharma.com/publicationsPlanning (accessed 2016-06-22).

15 David Healy, 'Let Them Eat Prozac', online at http://www.healyprozac.com (accessed 2016-0610).

16 Pisano, 'Can Science Be a Business?' 


\section{Diagnosing Epistemic and Ethical Problems}

\section{Applied Science}

Much ink has spilled debating the validity of the applied/pure distinction, and whether non-epistemic values play a different role in the applied versus pure sciences. ${ }^{17}$ There may be no sharp distinction between pure and applied, but some sciences have a built-in directionality. An applied science is a field of research that aims at discovering, elucidating, and in some sense mastering causal levers that can effect directional change of some specified property or set of properties in the world. The phrase 'causal levers' indicates intervention points: ways in which we can exert causal power and get things done. The property of interest need not be precisely, rigorously defined. There must be some means of roughly recognizing and measuring the property, even if particular cases and even overall measurement methods are disputed.

For example, conservation biology is an applied science that aims at causal levers that can be used to preserve or promote biodiversity. Biodiversity can mean many things. ${ }^{18}$ The concept might include sheer number of species (though the concept 'species' is itself much disputed), proportionality of species representation, genetic diversity, diversity at the level of higher taxa, phenetic or morphological diversity, degree of phylogenetic divergence, and more. Different methods of measuring biodiversity recognize or privilege some subset of these components. At the end of the day, despite disagreement on the nature of the property, conservation biologists elucidate factors that affect biodiversity. Conservation biology thereby generates tools that policy planners can use to promote biodiversity in particular cases of application.

The property of interest for medicine and medical research is health and its counterparts, disease, injury, and disorder. Applied science aims to enable directional change. One does not study conservation biology in order to reduce biodiversity or medicine in order to promote disease. In addition to the typical slate of epistemic values that characterize the goal of science in general, applied science is also guided by whatever values determine the direction of sought-after change. Both the choice of target property and direction of sought-after change are guided by non-epistemic values.

Moreover, in the case of medicine, the target property is inherently value-laden. The World Health Organization describes health as a positive state of well-being in itself, beyond the absence of disease. ${ }^{19}$ Health is essentially value-laden because it is a good that is necessary for individuals to pursue other goals of value. ${ }^{20}$ As Bergsma and Thomasma argue forcefully, health is not identical with its indicator measures, such as blood

17 See for example Martin Carrier and Patrick Finzer, 'Theory and Therapy: On the Conceptual Structure of Models in Medical Research', in Science in the Context of Application, edited by Martin Carrier and Alfred Nordmann (Springer, 2011), pp. 85-99; Sven Ove Hansson, 'Values in Pure and Applied Science', Foundations of Science 12:3 (2007), pp. 257-268; Ann Johnson, 'Everything New Is Old Again: What Place Should Applied Science Have in the History of Science?', in Science in the Context of Application, edited by Martin Carrier and Alfred Nordmann (Springer, 2011), pp. 455-466. 18 James MacLaurin and Kim Sterelny, What Is Biodiversity? (Chicago, IL: University of Chicago Press, 2008).

19 World Health Organization, 'WHO Constitution; 1948', in Official Records of the World Health Organization, 2 (1948), pp. 100-109.

${ }^{20}$ Norman Daniels, Just Health Care (New York, NY: Cambridge University Press, 1985). 
pressure, bile secretion, or urine production; health is the capacity to attain experiences of value. $^{21}$

To the extent that BMR discoveries do not enable promotion of health, BMR will fail to meet the goal of applied science. Grounds on which such a charge could be levied are empirical claims that BMR businesses are not innovative. ${ }^{22}$ Such failure is both epistemic and ethical, since the goal of applied science is knowledge, and both the target property and directionality encode moral values.

An immediate worry is 'invented diseases' and inappropriately medicalized conditions are not related to health at all. Research efforts that target these phenomena do not address health-related conditions and so fail to meet the goal of medicine qua applied science.

Another concern is the disconnection between clinical drug trials and the theoretical framework of medicine. Frequently these trials identify strategies to alleviate clusters of symptoms in the absence of an understanding of the causal structure whereby these strategies work. For example, gabapentin alleviates seizures in epileptic patients, but the mechanism of action is not understood. Gabapentin has also been correlated with relief of pain that is caused by a damaged sensory system, and with the discomfort of photorefractice keratectomy (the older form of laser eye surgery). Parts of the mechanism of action in the case of pain have been described though a complete account is lacking. ${ }^{23}$ Gabapentin is also prescribed off-label to treat anxiety disorders, bipolar disorder, attention deficit disorder, and restless legs syndrome. ${ }^{24}$ The disparate array of uses results from a shotgun approach to drug testing. Through documents obtained via a lawsuit, Vedula et al analyzed 21 clinical trials related to four types of off-label use of gabapentin. ${ }^{25}$ These studies target correlations between use of the study drug and changes in some measured symptom, in the absence of any causal understanding of the interaction between drug and targeted phenomenon. There are always cases like this in any body of science, but when large parts or even the majority of research produces correlations devoid of causal understanding, the status of the research comes into question. Identifying strategies for manipulating variables is not the same as elucidating causal levers within a scientific theoretical framework.

Moreover, the existence of the haphazard network of identified statistical correlations may actually hinder the progress of causal discovery. The phenomena measured as desired effects may not represent causally unified phenomena at all, at least with respect to the kind of causes that biomedical science identifies. Some identified correlations will reflect statistical artefacts; others are artificially combined effects of disparate causes. Thus the problem of failure to fit into theoretic frameworks is a failing

21 Jurrit Bergsma and David C. Thomasma, Autonomy and Clinical Medicine: Renewing the Health Professional Relation with the Patient, vol. 2 (Springer Science \& Business Media, 2000).

22 Reiss and Kitcher, 'Biomedical Research, Neglected Diseases, and Well-Ordered Science'.

23 Ankesh Kukkar et al., 'Implications and Mechanism of Action of Gabapentin in Neuropathic Pain', Archives of Pharmacal Research 36:3 (2013), pp. 237-251.

24 Alicia Mack, 'Examination of the Evidence for Off-Label Use of Gabapentin', Journal of Managed Care Pharmacy 9:6 (2003), pp. 559-568.

25 S. Swaroop Vedula, Tianjing Li, and Kay Dickersin, 'Differences in Reporting of Analyses in Internal Company Documents Versus Published Trial Reports: Comparisons in IndustrySponsored Trials in Off-Label Uses of Gabapentin', PLoS Med 10:1 (2013), e1001378. 
both for the research in question and for the larger scientific community that responds to the research.

If the charge that business BMR does not meet the goal of applied science is true, a natural question is what accounts for this failure? It may be that the overarching failure results from a problematic intrusion of nonepistemic values in the practice of science on the CRO model. Even if business BMR more successfully meets the overarching goal of applied science than the above points suggest and others have argued, lower level epistemic problems can be analyzed via models of the role of values within scientific practice.

\section{Externalist Model}

The lines of my critique can be broadly drawn by employing the externalist model of values in science, which differentiates internal scientific practice - investigation of causal levers - from target-setting and application stages of applied science. The externalist model allows that non-epistemic values affect decisions only outside the internal processes of good science. Non-epistemic values can affect the choice of research problems (usually via funding), and the application to which the research is put. Choice of research problem (before the internal science) will be enabled by considerations about enabling directional change in the target property. Values may impact application (after the internal science) by guiding the use of the causal levers that are explicated in the internal science.

On the externalist model, the influence of non-epistemic values on the internal processes (data collection, interpretation, evaluation, hypothesis acceptance, and so on) is strictly limited to ruling out certain methodological choices. For example human experimentation is narrowly restricted for ethical reasons. Apart from this, to the extent that non-epistemic values influence internal science, the science is flawed.

On the BMR business model, publication of study results is explicitly guided by business values. It might be argued that dissemination of results represents application of the internal science. However, the writer or writers of the study do not simply present raw data. Decisions about data format and methods of analysis (which data are to be analyzed by which statistical methods), and which results to discuss and highlight in the abstract and conclusion, reflect business values. Attention can be drawn to a selection of the significant results while ignoring side effects or null-results in certain groups of subjects.

The output of internal processes of applied science is knowledge about causal levers in the world. Data alone does not elucidate causal regularities or enable prediction and control. Interpretation of data is critical to fitting the research into the existing theoretical framework of science. In turn this fit is critical to the understanding of causal levers that applied science targets. The externalist model prescribes the exclusion of nonepistemic values from the process of scientific inference and discovery. Interpretation of data is part of the critical, fruitful process of scientific inference. BMR on the business model thus violates the externalist normative proscription of non-epistemic values in internal science. To the extent that the externalist model highlights problematic intrusions of values, the model flags as problematic the role of business values in CRO research.

\section{Longino's Model}

The externalist model has been much criticized as unrealistic, impossible, and unnecessary. Various authors have proposed ways in which values can influence internal 
science without thereby sullying it. Helen Longino argued convincingly that values can affect the internal processes of science without researchers being conscious of this intrusion. ${ }^{26}$ Indeed, Longino's approach suggests that non-epistemic values will inevitably affect internal science. Values affect even the fundamental matter of whether some particular observation counts as evidence or not, because values inform background assumptions that underlie observation. It is unclear how widespread and how unavoidable the intrusion of values is on Longino's picture. It is clear, however, that non-epistemic values can and will enter some areas of research without scientists' awareness of the intrusion. The critical issue is whether this intrusion compromises scientific objectivity, resulting in failure to meet the goals of science.

Longino argues that objectivity is a function of the social nature of science. Science is objective to the degree that transformative criticism is possible. Longino identifies four requirements for the possibility of transformative criticism: (1) recognized avenues of criticism (for example peer review in public forums); (2) shared standards, both epistemic and social (e.g. empirical adequacy, consistency with accepted theories in other domains, relevance to or satisfaction of social needs); (3) community responsiveness to criticism; (4) equality of intellectual authority. ${ }^{27}$

Within itself, a CRO does not meet these requirements. Contributors have rank and status as employees in a hierarchical structure that precludes equal intellectual authority. The CRO responds to economic pressures and contract stipulations, but to scientific criticism only to the extent that such criticism relates to those concerns (for example when scientific problems damage the chances of securing contracts). Much of the inner workings of CRO studies are immune to criticism as a result of their decentralization. Each employee has access to a very narrowly limited portion of the drug development process, and no particular employee knows enough to critique the overall process and output.

BMR on the business model lacks Longino's prescribed objectivity when considered within the social structure of medical science at large. Companies publish in journals that are broadly recognized as forums for criticism. However, BMR business does not share standards with academic and publically funded medical researchers. These researchers, who represent the potential critics of the BMR business' work, share standards among themselves. BMR business standards differ, and expectedly so, as the standards reflect the companies' economic interests. CRO practice diverges from academic requirement for disclosure of all data, registration of trials, study authorship, and attribution of credit and responsibility for activities within studies. More broadly, BMR business has no direct concern for expansion of knowledge frameworks or consistency with widely accepted scientific theories, epistemic values that underlie scientific standards Longino. Both the existence of and the content of the communal standards enable the community to effectively pursue the goal of applied science. Subverting these standards compromises the ability of the community to produce and respond to criticism that enables objectivity.

By strategically planning study publication, and by virtue of sheer volume of studies, pharmaceutical companies can dominate public fora. Because ghost-written studies by their very nature do not reveal true authorship or funding, it is extremely

${ }^{26}$ Longino, Science as Social Knowledge.

27 Ibid. 
difficult to quantify precisely how much of the literature is produced by CROs. The Pfizer sertraline document (discussed in section 2) indicates that Pfizer alone was responsible for a significant portion of all scientific literature published on sertraline throughout the 1990s. Healy and Cattell claim that, as of early 2001, Current Medical Directions (hired by Pfizer) was responsible for 55 publications on the therapeutic effects of sertraline. ${ }^{28} 41$ studies had been published (apparently) independently of Current Medical Directions. The overall impact of Pfizer's studies is even greater than this figure suggests, because Current Medical Directions carefully selected well-known authors and journals. Sismondo claims that the Pfizer-funded studies have been cited at about three times the rate of (apparently) non-Pfizer studies. ${ }^{29}$ Public scientific forums can be dominated to such an extent that academic researchers cannot exercise equal intellectual authority, because each critical voice is effectively drowned out.

The current structure of BMR business results in concealment of research funding. This is not a deliberate, nefarious plot to avoid scientific accountability, but an unsurprising result of efficient business decentralization. The study author is paid to affix his/her name to the publication and has no need to know the ultimate source of study funding. The appearance of study independence better serves the business' advertising purposes, but again, this should not be seen as a calculated ploy to evade scientific standards. BMR business just does not consider scientific standards of disclosure in the first place.

It is implicit in Longino's requirement for equal intellectual authority that participants in scientific discourse are not anonymous. One cannot ensure that a participant's authority is equal without some knowledge of the participant's identity. The problem with ghost-authorship is more fundamental than the anonymity of an individual participant, however. Because of the decentralized structure of BMR business, no single person qualifies for study authorship by the standards of the International Committee of Medical Journal Editors. The published study is the scientific vehicle for discussion and possible criticism, but it is unclear who exactly represents the BMR business in the public forum. It is problematic to assign any intellectual authority to a 'ghost' that represents the disparate efforts of lab workers, study coordinators, and professional writers. Standards for transparency in research and research reporting, such as those advocated by the Center for Open Science, ${ }^{30}$ would not solve this conceptual problem.

\section{Douglas' Model}

The problems raised by publication planning in particular are brought out by Heather Douglas' model of the role of values in science. ${ }^{31}$ Douglas argues that problems arise when non-epistemic values are given what Douglas calls a direct role in internal science: when non-epistemic values are taken to be evidential. However, non-epistemic values may play an indirect role without compromising scientific objectivity. Douglas further argues that non-epistemic values normatively ought to enter into decisions within the internal processes of science. Scientists must bear responsibility for the possibility of

28 David Healy and Dinah Cattell, 'Interface between Authorship, Industry and Science in the Domain of Therapeutics', The British Journal of Psychiatry 183:1 (2003), pp. 22-27.

29 Sismondo, 'Ghost Management'.

30 B. A. Nosek et al., 'Promoting an Open Research Culture', Science 348:6242 (2015), pp. 1422-1425.

31 Douglas, Science, Policy, and the Value-Free Ideal. 
foreseeable harm resulting from methodological decisions. Though public involvement can be helpful at various stages of science, some methodological choices (for example, whether particular slides of rat livers show malignant or benign tumors) can only be made by the scientist with his/her scientific expertise. All such decisions carry some risk of epistemic error. When such error would result in public harm, scientists must employ non-epistemic values to choose what degree of certainty is required in making the decision (for example, to score a slide 'benign'). This can take the form of balancing the risk of Type I vs. Type II errors. From a public health standpoint, the risk of erroneously deeming a carcinogenic chemical safe typically carries more dire consequences than the risk of erroneously deeming a harmless chemical carcinogenic. Privileging public health above industrial profits involves non-epistemic values. The responsible scientist can and should explicitly privilege public health in decisions about Type I vs. Type II error tradeoffs. If scientists were to disavow this ethical responsibility the result must compromise scientific autonomy. Outside agents could bear the responsibility only through a level of oversight that would effectively hamstring the scientific community.

Douglas' arguments ultimately stem from claims about the nature of science and its progress. The externalist ideal of excluding values from science has the goal of preventing values from being mistaken for evidence. The worry is that wishful thinking will lead to faulty inferences. As Brown has argued, the complete exclusion of values from science is too crude a solution for this worry. ${ }^{32}$ Rather, an adequate account of the success of science requires situating research programs in their social and ethical contexts .33 A scientific community is both an epistemic and ethical community, and scientists qua persons are morally responsible agents. The idea of taking off one's 'moral responsibility hat' is untenable. Ethical responsibility for the risk of epistemic error is at once an individual and communal responsibility that attaches to scientists as morally responsible agents. Moreover, scientists bear role responsibilities not to hinder the success of science, as the compromise of scientific autonomy would do.

Douglas' model highlights a critical problem for CRO research that results from its decentralized structure. Because of the extreme specialization and narrow bounding of each employee's role, responsibility becomes impossibly diffuse. No particular individual within the drug development process bears responsibility for potential harms caused by the eventual marketing of the drug. This claim might seem to conflict with the earlier argument that company-favoring bias accumulates at each node of the diffuse study process. The key is that each employee can subtly favor company interests when making methodological choices, without actually knowing the potential non-epistemic risks of epistemic error. There are no incentives for noticing unexpected and potentially harmful side-effects. Such side-effects are not the concern of the technician recording chemical data or the analyst applying statistical models. Each employee works to further company interests, but without knowledge of the potential consequences of the total project.

32 Matthew J. Brown, 'Values in Science Beyond Underdetermination and Inductive Risk', Philosophy of Science 80:5 (2013), pp. 829-839.

33 Heather Douglas, 'The Moral Terrain of Science', Erkenntnis 79:5 (2014), pp. 961-979; Janet A. Kourany, 'Meeting the Challenges to Socially Responsible Science: Reply to Brown, Lacey, and Potter', Philosophical Studies 163:1 (2013), pp. 93-103. 


\section{Elliott's Model}

Having shown that consideration of non-epistemic values is necessary for scientific responsibility, the question is which values and how. Kevin Elliott provides guidance on how to responsibly include non-epistemic values within scientific practice. ${ }^{34}$ Elliott's central claim is that at critical decision-points, there must be appropriate representation of all relevant stakeholders. He diagnoses the role of non-epistemic values in four areas: (1) choosing research projects and study designs; (2) creating scientific definitions and terminology, (3) evaluating and interpreting evidence (studies), and (4) applying research, including decisions about how to disseminate research results. Elliott's critique is that 'contemporary research tends to be dominated by the values of just a few groups (especially industry and the military) that happen to have deep pockets' ${ }^{35}$ On Elliott's view, non-epistemic values should not be entirely excluded from the internal processes of science. Rather, the goal should be bringing policy-relevant scientific research into alignment with the values of the public at large, rather than a small set of wealthy stakeholders.

Because of the publication advantages of the BMR business model, pharmaceutical companies are over-represented in biomedical science in the way that Elliott warns against. BMR on the business model chooses research projects likely to generate profits. These choices result in the phenomenon of 'neglected diseases', ${ }^{36}$ such that the interests of many members of the public are not represented. If 'public interest' is taken to include the global population, certainly the problem of neglected diseases represents a severe departure from representation of public interests in BMR. Even if public interest is restricted to the concerns of the US population (since biomedical research in the US is the focus of this paper), US citizens all share an interest in justice not only for the global community but for even extreme minority populations afflicted with rare neglected diseases in the US.

Running multiple trials at multiple geographic sites, with no requirement that each trial run to completion, enables companies to choose trials and develop studies that further business aims to the detriment of public interest in the evaluation of evidence (Elliott's point 3). Publication planning introduces business values into decisions about how to disseminate research results (Elliott's point 4), in ways that may run counter to public interest.

Considering Elliott's second locus of concern, scientific definitions and terminology, also illustrates ways in which BMR on the CRO model does not reflect public values. CROs choose terminology that furthers marketing aims, including the rebranding of marketing itself as 'scientific finding allocation and dissemination' ${ }^{37}$ Disease categories reflect business values. The oft-cited example, 'Pre-menstrual Dysphoric Disorder', represents an 'invented disease' created by the pharmaceutical companies in order to generate demand for a product (drug treatment). The definition of Major Depressive Disorder as a list of symptoms, regardless of context, enables companies to market drugs to individuals that Horwitz and Wakefield argue are merely rationally sad

\footnotetext{
34 Elliott, Is a Little Pollution Good for You?

35 Ibid., p. 5.

36 Reiss and Kitcher, 'Biomedical Research, Neglected Diseases, and Well-Ordered Science'.

37 Pharma, 'Publications Planning', 31 March 2009.
} 
(owing to romantic or career loss, or other life circumstance) rather than sick. ${ }^{38}$ From the business perspective, it does not matter whether individuals are diseased or not; the business need not consider this question. In its own lights, the pharmaceutical company invents a marketing vector, not a disease.

It is important to note that the public often benefits from the products developed to treat medicalized conditions. Erectile dysfunction is a medicalized condition; the fact is that many individuals want and are now able to obtain drugs that benefit them. Medicalizing the condition can help individuals view the issue without blaming themselves. On the other hand, medicalizing phenomena can make people think that they have problems when in fact they do not, particularly when symptoms are vague. Drugs often have harmful side effects. Moreover, medicalization can change societal norms in harmful ways. Equating maleness, energy level, and testosterone level, as in 'low- $\mathrm{T}$ ' advertising, may be broadly harmful. Given that there are potential benefits and harms associated with biomedical research, the critical point is that value-laden questions need to be addressed: public values must be represented in addition to business values.

\section{Intervention}

Goldacre's recent critique of commercialized biomedical research shed much-needed light on the problems addressed throughout this paper. ${ }^{39}$ Resulting calls for transparency in industry-funded research will not suffice to resolve the problems. Part of the reason is practical: many companies simply aren't conforming to legal requirements, and there are not sufficient mechanisms for enforcement. ${ }^{40}$ Moreover, it is unclear that making problems visible will resolve them. For example, identifying occurrences of ghost authorship does not resolve the problem that no individual can bear responsibility for the published study. Critically, Goldacre highlights the ethical cost of inaction. Marketing new drugs that are less effective, and potentially less safe, than existing treatments results in greater suffering than would result from scientifically responsible comparison of new treatments to existing treatments. In addition to this direct harm, philosophical work has shown that problematic intrusion of values in science compromises the effectiveness of science and the very reason that we have science in the first place. ${ }^{41}$

These problems cannot be isolated to the for-profit sector. The high volume of research that is conducted along the decentralized model and its integration within the biomedical research community imply that the entire community of biomedical research

38 Allan V. Horwitz and Jerome C. Wakefield, The Loss of Sadness: How Psychiatry Transformed Normal Sorrow into Depressive Disorder (Oxford: Oxford University Press, 2007).

39 Goldacre, Bad Pharma.

40 Jennifer E. Miller, David Korn, and Joseph S. Ross, 'Clinical Trial Registration, Reporting, Publication and FDAAA Compliance: A Cross-Sectional Analysis and Ranking of New Drugs Approved by the FDA in 2012', BMJ Open 5:11 (2015), e009758; Amelia Scott, Julia J. Rucklidge, and Roger T. Mulder, 'Is Mandatory Prospective Trial Registration Working to Prevent Publication of Unregistered Trials and Selective Outcome Reporting? An Observational Study of Five Psychiatry Journals That Mandate Prospective Clinical Trial Registration', PloS one 10:8 (2015), e0133718; Monique L. Anderson et al., 'Compliance with Results Reporting at Clinicaltrials.Gov', New England Journal of Medicine 372:11 (2015), pp. 1031-1039.

41 Douglas, 'The Moral Terrain of Science'. 
science is compromised. The analysis cannot be confined to contract research organizations independently of the scientific community in which they publish. This point is borne out most clearly by the compromise of communal mechanisms for ensuring scientific objectivity identified by Longino's model. ${ }^{42}$

In this paper I have used philosophical models of the structure of science and values to show the structural causes of the epistemic and ethical problems with BMR on the CRO model. Claims that science and business can be seamlessly integrated are overly simplistic, but so too are claims that the problems with for-profit BMR result from greed. Casting problems in terms of greed erroneously attributes agency and intentionality to corporate structures that are not proper subjects of these individualized concepts.

The disconnection between BMR business and objective science, on whichever model, ultimately stems from the disconnection between the goals of a business versus an applied science. Qua business, BMR need not aim at causal levers that can be used to promote health or fight disease. I have claimed that the disease concept itself is not needed for BMR business, and it seems clear that no concept of health is required either. Biological endpoints must be specified and measured, but these will be determined by business rather than scientific concerns.

Problems with the achievement of scientific goals stem from the goal and conditions required to meet the goal of BMR business - if BMR businesses do not seek profit, they fail. Companies have evolved to operate along the model described in this paper. The identified problems might be relieved or resolved by altering the conditions necessary to achieve business goals. Given that many of the problems arise through the decentralization of scientific functions, proposed interventions might succeed by relieving the market pressures that drive decentralization.

Reiss' proposal to create a publically-operated central research organization that draws fees from industrial clients faces the problem that research results reliably track funding source due to hidden biases. ${ }^{43}$ Moving the source of funding back one level likely would not affect hidden biases. However, centralization of the research trial phase can reconcile some of the structural issues discussed in this paper, and remove incentives for decentralization at other phases.

Brown's more radical suggestion to socialize biomedical research funding relieves market pressures by the direct expedient of removing biomedical research from the marketplace. ${ }^{44}$ Brown suggests that socialized clinical medicine should serve as a successful model for socializing BMR. In this spirit, one possibility is a 'two-tiered' approach to BMR. In the current system, BMR companies can effectively dominate medical journals. In order to ensure public forums for transformative criticism, a distinct set of research journals might publish only publically funded studies. This can be done by registering the recipients of public funding and preventing them from accepting additional private funding.

Ensuring the success of this sort of public program will require massive funding, if only to attract some scientists away from the private sector. The extreme success of the

\footnotetext{
42 Longino, Science as Social Knowledge, p. 19.

43 Reiss, 'In Favour of a Millian Proposal to Reform Biomedical Research'.

44 James Robert Brown, 'The Community of Science ${ }^{\circledR}$ ', in The Challenge of the Social and the Pressure of Practice: Science and Values Revisited, edited by Martin Carrier, Don Howard, and Janet A. Kourany (Pittsburgh: University of Pittsburgh Press, 2008), pp. 189-216.
} 
top dozen pharmaceutical giants suggests that targeted corporate tax increases are economically feasible and can be of great help in the near term. In the long term, the cost of public funding now must be considered alongside the total economic cost and benefits of biomedical knowledge and health outcomes at a broad scale.

Although the analysis of this paper suggests that either of the two proposals would ameliorate problems with commercialized BMR, the plain fact is that both proposals face extreme practical challenges. Each proposal requires large-scale regulatory changes that are unlikely to come about in the present political and social climate. Another approach is possible. The critical factor underlying the epistemic and ethical problems is the decentralized structure of CRO research. Yet this factor appears to be present in other areas of contemporary science, seemingly without compromising objectivity. For example in the field of high-energy particle physics, recent papers include hundreds and sometimes thousands of authors, representing an extreme diffusion of responsibility. Further philosophical work can shed light on why such cases do not appear to violate Douglas' prescription for ensuring responsibility in scientific inquiry. Analysis of decision-making and responsibility in the context of extreme diffusion of research roles may suggest alternative solutions to the problems rooted in the decentralized structure of $\mathrm{CRO}$ research.

Regardless of criticism and disagreement about particular proposed interventions, here is a place where philosophers of science can contribute to crucial social issues. Philosophic engagement is crucial, in keeping with the tradition of socially engaged philosophy going back to the Vienna Circle (and indeed further).

Aleta Quinn, Smithsonian Institution aletaquinn@gmail.com

\section{Bibliography}

Anderson, Monique L., Karen Chiswell, Eric D. Peterson, Asba Tasneem, James Topping, and Robert M. Califf. 'Compliance with Results Reporting at Clinicaltrials.Gov', New England Journal of Medicine, 372:11 (2015), pp. 1031-1039.

Azoulay, Pierre. 'Capturing Knowledge within and across Firm Boundaries: Evidence from Clinical Development', The American Economic Review, 94:5 (2004), pp. 1591-1612.

Bergsma, Jurrit, and David C. Thomasma. Autonomy and Clinical Medicine: Renewing the Health Professional Relation with the Patient. Vol. 2. Springer Science \& Business Media, 2000.

Brown, James Robert. 'The Community of Science ${ }^{\circledR}$ ', in The Challenge of the Social and the Pressure of Practice: Science and Values Revisited, edited by Martin Carrier, Don Howard and Janet A. Kourany, Pittsburgh: University of Pittsburgh Press, 2008, pp. 189-216.

Brown, Matthew J. 'Values in Science Beyond Underdetermination and Inductive Risk', Philosophy of Science, 80:5 (2013), pp. 829-839.

Carrier, Martin, and Patrick Finzer. 'Theory and Therapy: On the Conceptual Structure of Models in Medical Research', in Science in the Context of Application, edited by Martin Carrier and Alfred Nordmann (Springer, 2011), pp. 85-99.

Daniels, Norman. Just Health Care. New York, NY: Cambridge University Press, 1985. 
Douglas, Heather. Science, Policy, and the Value-Free Ideal. Pittsburgh, PA: University of Pittsburgh Press, 2009.

Douglas, Heather. 'The Moral Terrain of Science', Erkenntnis, 79:5 (2014), pp. 961-979.

Elliott, Kevin Christopher. Is a Little Pollution Good for You? Incorporating Societal Values in Environmental Research. Oxford: Oxford University Press, 2010.

Envision Pharma. 'Publications Planning', http://envisionpharma.com/publications planning/, 27 September 2008, online at https://web.archive.org/web/ 20080927093133/http://www.envisionpharma.com/publicationsPlanning (accessed 2016-06-22).

Envision Pharma. 'Publications Planning', http://envisionpharma.com/publications planning/, 31 March 2009, online at https:/ / web.archive.org/web/20090331060139/ http://www.envisionpharma.com/publicationsPlanning (accessed 2016-06-22).

Goldacre, Ben. Bad Pharma: How Drug Companies Mislead Doctors and Harm Patients. New York: Faber \& Faber, 2014.

Hansson, Sven Ove. 'Values in Pure and Applied Science', Foundations of Science, 12:3 (2007), pp. 257-268.

Healy, David. 'Let Them Eat Prozac', online at http://www.healyprozac.com. (accessed 2016-06-10).

Healy, David, and Dinah Cattell. 'Interface between Authorship, Industry and Science in the Domain of Therapeutics', The British Journal of Psychiatry, 183:1 (2003), pp. 22-27.

Horwitz, Allan V., and Jerome C. Wakefield. The Loss of Sadness: How Psychiatry Transformed Normal Sorrow into Depressive Disorder. Oxford: Oxford University Press, 2007.

International Committee of Medical Journal Editors. 'Defining the Role of Authors and Contributors', online at http:/ / www.icmje.org/recommendations/browse/roles-andresponsibilities/defining-the-role-of-authors-and-contributors.html. (accessed 201606-10).

Johnson, Ann. 'Everything New Is Old Again: What Place Should Applied Science Have in the History of Science?', in Science in the Context of Application, edited by Martin Carrier and Alfred Nordmann (Springer, 2011), pp. 455-466.

Kourany, Janet A. 'Meeting the Challenges to Socially Responsible Science: Reply to Brown, Lacey, and Potter', Philosophical Studies, 163:1 (2013), pp. 93-103.

Kukkar, Ankesh, Anjana Bali, Nirmal Singh, and Amteshwar Singh Jaggi. 'Implications and Mechanism of Action of Gabapentin in Neuropathic Pain', Archives of Pharmacal Research, 36:3 (2013), pp. 237-251.

Lexchin, Joel. 'Clinical Trials in Canada: Whose Interests Are Paramount?', International Journal of Health Services, 38:3 (2008), pp. 525-542.

Longino, Helen E. Science as Social Knowledge: Values and Objectivity in Scientific Inquiry. Princeton, NJ: Princeton University Press, 1990.

Mack, Alicia. 'Examination of the Evidence for Off-Label Use of Gabapentin', Journal of Managed Care Pharmacy, 9:6 (2003), pp. 559-568.

MacLaurin, James, and Kim Sterelny. What Is Biodiversity? Chicago, IL: University of Chicago Press, 2008.

Miller, Jennifer E., David Korn, and Joseph S. Ross. 'Clinical Trial Registration, Reporting, Publication and FDAAA Compliance: A Cross-Sectional Analysis and Ranking of New Drugs Approved by the FDA in 2012', BMJ Open, 5:11 (November 1, 2015), e009758. 
Mirowski, Philip, and Robert Van Horn. 'The Contract Research Organization and the Commercialization of Scientific Research', Social Studies of Science, 35:4 (2005), pp. 503548.

Nosek, B. A., G. Alter, G. C. Banks, D. Borsboom, S. D. Bowman, S. J. Breckler, S. Buck, et al. 'Promoting an Open Research Culture', Science, 348:6242 (2015), pp. 1422-1425.

Pisano, Gary. 'Can Science Be a Business?', Harvard Business Review 84:10 (2006), p. 114.

Reiss, Julian. 'In Favour of a Millian Proposal to Reform Biomedical Research', Synthese, 177:3 (2010), pp. 427-447.

Reiss, Julian, and Philip Kitcher. 'Biomedical Research, Neglected Diseases, and WellOrdered Science', Theoria, 24:3 (2009), pp. 263-282.

Scott, Amelia, Julia J. Rucklidge, and Roger T. Mulder. 'Is Mandatory Prospective Trial Registration Working to Prevent Publication of Unregistered Trials and Selective Outcome Reporting? An Observational Study of Five Psychiatry Journals That Mandate Prospective Clinical Trial Registration', PloS one, 10:8 (2015), e0133718.

Sismondo, Sergio. 'Ghost Management: How Much of the Medical Literature Is Shaped Behind the Scenes by the Pharmaceutical Industry?', PLoS Medicine, 4:9 (2007), e286.

Sismondo, Sergio, and Scott Howard Nicholson. 'Publication Planning 101', Journal of Pharmacy \& Pharmaceutical Sciences, 12:3 (2009), pp. 273-279.

Vedula, S. Swaroop, Tianjing Li, and Kay Dickersin. 'Differences in Reporting of Analyses in Internal Company Documents Versus Published Trial Reports: Comparisons in Industry-Sponsored Trials in Off-Label Uses of Gabapentin', PLoS Medicine 10:1 (2013), e1001378.

World Health Organization. 'WHO Constitution; 1948', in Official Records of the World Health Organization, 2 (1948), pp. 100-109. 